\title{
OBSERVATIONS ON THE FREQUENCY CHARACTERISTICS OF THE THRESHOLD OF AUDIBILITY IN PERCEPTIVE IMPAIRMENT.
}

\section{By}

\author{
J. UKIDA \\ (Fron The Okayama Medical College)
}

The author carried out hearing tests on these cases, which showed obvious perceptive impairment on clinical examination, in a soundproof room equipped with a calibrated $2-A$ audiometer. The author examined the frequency characteristic of threshold of audibility and furthermore the relation between the threshold shift and the location of lesions.

The results and discussion could be summarized as follows:

1) The majority of these cases had impaired hearing for high tones; onethird of them showed impairment for all tones; in some of them elevation of the lower tone limit was observed.

2) Generally speaking, when the acoustic nerve is impaired, the hearing loss beginning with high tone range could be observed. But when the lesions are in the cochlea, various types of frequency characteristics in audibility could be observed.

3) In a case in which both the tympanic membrane and Eustachian tube were intact, there was found no lengthening of bone conduction by applying a low toned tuning fork, and yet there is impaired hearing for high tones, it would be almost safe to conclude that this case was perceptive impairment, namely it was especially a lesion of the acoustic nerve itself or that of the lower basal part of the cochlea. But it is unsafe to say that a case cannot be perceptive impairment when there is no loss of hearing for high tones.

\section{A HEALED CASE OF PRIMARY CARCINOMA OF THE AURICLE.} By

\author{
I. NAKAGAWA. \\ (Depertment of Oto Laryngology, Tokio Jikeikai Medical College and \\ Hospital of the Cancer Institute)
}

A man aged 63 had notiched a tumor since 3 years on his left auricle. The tumor started to increase rapidly in size since a year, producing swelling both on, the anterior and posterier aspects, which was examined microscopi- 
cally and diagnosed as a primary squamous-celled cancer. Treatment both with $\mathrm{X}$-Ray (2400 r), Redium and Radium Needles (during a week, total dose amounting to $21660 \mathrm{mg}$ hours) succeeded to make the growth to disaprear completely. Since then now about a year and a half, there is no sign of recurrence, neither any trace of lymph node metastase.

\section{REPORT OF CASES OF PENDULOUS TONSILS}

By

K. AKAIKE

(Department of Oto-Rhino-Laryngology, Tokyo Hospital of

Communication Minis'ry)

Among three cases of Pendulous Tonsils, seen during the past three years; one complained hoarse voise, snoring, and short breath when running. The third case had a feeling of something stuck in the throat. All these symptoms had developed after suffering from Angina. There were no abnormalities found in general body growth but there were signs of tuberçulous disposition in all three cases. The histologic findings and the mode of development led to the inference that a Hamartoma or a Hamartoblastoma had become productive as an effect of local inflammation.

\section{STUDIES ON THE MISHEARING OF SOUNDS}

By

S. HANDA.

(From the Otological Department, Medical School, Unizersity of Nagoya.)

The Power of hearing both of musical tones and of speech sounds was examined on 73 persons with impaired hearing by 'means of Hartman's tuning fork $\mathrm{C}, \mathrm{C}, \mathrm{C}_{2}, \mathrm{C}_{3}$ and $\mathrm{C}_{4}$ ) and the sounds of spoken syllables (ka, mo, re etc.).

During this experiment they were required to write down the syllables as they cought.

By this examination, (1) the relation between the power of hearing for musical tones and that for speech sounds and (2) the tendency of mishearing were found as follows:

I. In order to hear sounds clearly, such a bigh tone as $\mathrm{C}_{f}$ is far more 